\title{
Study Subject Digital Photograph
}

National Cancer Institute

\section{Source}

National Cancer Institute. Study Subject Digital Photograph. NCI Thesaurus. Code

C115496.

A digital photograph taken of a study participant for use in a clinical trial. 